\title{
Rehabilitation Process for Parkinson Disease Patient using Exergames
}

\author{
Muhammad Fairuz \\ Abd Rauf \\ Faculty of Computer \\ Science and \\ Information Technology, \\ Universiti Selangor, \\ Malaysia
}

\author{
Mohd Fahmi \\ Mohamad Amran \\ Computer Science \\ Department, \\ Faculty of Defence \\ Science and Technology, \\ National Defence \\ University of Malaysia
}

\author{
Suziyanti Marjudi \\ Faculty of Computer \\ Science and \\ Information Technology, \\ Universiti Selangor, \\ Malaysia
}

\author{
Nur Amlya Abd Majid \\ Faculty of Computer \\ Science and \\ Information Technology, \\ Universiti Selangor, \\ Malaysia
}

\begin{abstract}
The increasing rate of $\mathrm{PD}$ patient requires more creative approach to assist in the rehabilitation process. Support group such as Malaysian Parkinson Disease Association or MPDA normally carry out activities such as dancing and Tai Chi have limited space to cater to all PD patient at once. Rehabilitation process involves cost including cost for transportation and registration fees for patient to go to rehab center. On the other hand, rehabilitation processes are boring and that makes the patient unable to carry out the rehabilitation process consistently. Although exergames have been in the market for three decades now, it still lacks on focus on users with special needs. Most exergames are developed for healthy people. There are a few exergames developed for PD patient but the tools involved for them to play or indirectly rehab them is not suitable since it requires them to hold an item. PD patient have tremors and this will make it difficult for them to enjoy the game. It is crucial for developer to design games with the objectives for particular rehabilitation needs and capabilities as well as the target population. Certain exergames developed for PD patient are too challenging and this fails to motivate PD patient. Up to this point, limited research has been conducted for hand eye coordination. The purpose of this research is to identify and propose a framework that enables development of application for patient with Parkinson disease to carry out rehab based on their stages.
\end{abstract}

\section{Keywords}

Kinect, exergames, Parkinson, framework

\section{INTRODUCTION}

James Parkinson wrote an article entitled 'Essay on the Shaking Palsy' [1]. This is one of the first researches that focus on Parkinson Disease (PD). PD is one of the most common neurological disorders that can be seen through motor and nonmotor features [2]. Jean-Marin Charcot contribution was immense in identifying most symptoms in PD. He managed to identify tremor, rigidity, postural instability and bradykinesia. $\mathrm{He}$ even renamed the disease previously known as 'Paralysis Agitants' to PD as a tribute to James Parkinson for his contribution in research regarding PD [3].

Six symptoms that relates to motor have been identified. One of the earlier signs of PD is tremor. Normally it can be seen when the patient is resting. It is also known as rest tremor. The movement of one or more body parts shows pattern of tremble but normally it is lost when the patient tends to carry out voluntary movement. Stiffness or inflexibility of movement is also one of the symptoms of PD. Also known as rigidity, it is caused by excessive contraction of muscles [2]. Other symptoms which affect daily routine of $\mathrm{PD}$ patient is slowness of movement otherwise known as bradykinesia. It seriously deteriorates the quality of life of a PD patient since it directly affects daily routines such as writing, eating and even getting dressed. Hand asymmetry is another symptom of PD. It is a combination of one of the following, bradykinesia and tremor that causes this symptom. Generally, it affects movement and responsiveness of the hand. Researcher and patient found that difficulty to stand is another symptom of PD. Also known as posture instability, this symptom is like losing the center of gravity thus makes it hard for the patient to stand. The last symptom of PD is freezing of gait. This is yet the worst stage where it prohibits patient to carry out any voluntary movements [4].

Non-motor symptoms affect PD patient as well. Neuropsychiatric features, dysautonomia, sleep disorders, sensory dysfunction, pain and fatigue have been identified as non-motor symptom [5]. PD patient tend to have depression, hallucinate and even constipation. These surely affect their quality of life. In order to diagnose PD, patient with assist from the caretaker have to answer set of questionnaire also known as PD Questionnaire 39 (PDQ 39). PDQ 39 is a set of questionnaire with 39 questions which can assist the doctor or specialist. PDQ 39 covers eight aspects of quality of life including mobility, activities of daily living, emotional wellbeing, stigma, cognition, communication and bodily discomfort (Jenkinson et al., 1997). PDQ 39 also is translated in forty languages (Huang et al., 2011).

Three main method that is used to treat PD includes taking medicines (drugs), operation and rehabilitation process. Further information regarding drugs and medicine will be discussed in Chapter 2. There are various rehabilitation methods for PD. Tai-Chi, dance movement, speech therapy and group therapy are all part of the rehab process to help PD patient. UPDRS is another set of questionnaire that is to monitor and evaluate the longitudinal course of a PD patient. This includes how effective is the drugs, operation or even the rehabilitation process. Until the time of this research been conducted, no cure has been found and treatments able to only control the symptoms and improving quality of life of PD patient. Figure 1.1 provides overview regarding PD.

Until now, researches are still working towards finding a solution for Parkinson disease which includes treatment for motor or non-motor symptoms. Researches which are not limited to medical background are involved with improving the quality of life of PD patient. For example, Tai Chi is proven to 
improve stability of PD patient [8]. Even mobile phone is used to assist in rehabilitation or diagnostic process of PD patient. Food are also being studied to help development of PD patient [9]. Nowadays, technology have provided more options for PD patient to carry out rehabilitation in a fun manner. Its involvement to improve quality of life of a PD patient cannot be denied. Process of diagnostic and rehab can be carried out using the latest technologies. Companies such as Microsoft, Sony and Nintendo have invested in a new concept of gaming known as exergames. Exergames is a combination of exercise and games where it involves body movement of players. It can be used as a rehabilitation tools due to the fact that it is reliable and quantifiable [10]. Even diagnostic process can be conducted through exergames [11] because the price is relatively cheap [12]. Games have been chosen as a rehab tools because it manage to increase motivation in rehabilitation sessions caused by tedious process of carry out almost the same daily activities [13]. This research will focus on rehabilitation process for PD patient through exergames and Microsoft Kinect is to be used as tools to assist in the process.

\section{OVERVIEW}

\subsection{Problem Statement}

The increasing rate of PD patient requires more creative approach to assist in the rehabilitation process. Support group such as Malaysian PD Association (MPDA) normally carried out activities such as dancing and tai chi which have limited space to cater to all PD patient at once. Current technology using conventional $3 \mathrm{D}$ video-based motion analysis requires large space, expensive and requires expertise (Galna, Barry, et al., 2014) Due to high numbers of PD patients, it is encourage to carry out home rehabilitation due to the high costs [15] including cost for transportation and registration fees for patient to go to rehabilitation center [16].

Although exergames have been in the market for three decades now, it still lack on focus on users with special needs [17]. Most exergames are developed for standard and regular people without diseases. Although it is proven that rehabilitation for PD patient is a success by a long repetitive treatment made of exercises [18], there are a few exergames developed for PD patient but some of the tools involved for them to play or indirectly rehabilitate them is not suitable since it requires them to hold an item [10]. PD patient have tremors and this will make it difficult for them to control a device and enjoy the game. Conventional method of assessment using questionnaire have its own drawbacks since it has issue with accuracy and consistency of results [19]. This is due to the fact that data can be collected when the patient visited doctor and can only happen at the specific time. More consistent data collection method is required where a tools or method that can gather data while the patient is in a normal state and not stressed out [11]. Currently, exergames have limited user data input and data collection [17]. Accurate assessment of movement on a consistent basis enables clinician and researchers to monitor disease progression.

It is crucial for developer to develop games with the objectives for particular rehabilitation needs and capabilities as well as the target population [20]. Certain exergames developed for PD patient are too challenging [21] and fails to motivate the patient. Up to this point, no research so far to detect voice tremor although exergames tools such as Kinect can be used to do it [22]. Further research is required to study about the effectiveness of using exergames as rehabilitation tools. In ensuring success of designing exergames as rehabilitation tools, few items have to highlighted which include target specific clinical features, easier than commercial games, avoid negative feedback, clear targets, increase difficulty level slowly and design a new exergames tools which do not requires platforms and handheld controller [10]. Finally, stimulating a person interest is key in ensuring success of rehabilitation process or exercise [23]. This paper lays out the proposed research project under the area of rehabilitation process for parkinson disease patient.

\subsection{Objectives}

This study focuses on the following objectives:

1. To develop a conceptual framework that enables development of game-based rehabilitation for patient with PD.

2. To verify the conceptual framework by developing prototype of exergames to rehabilitate PD patient.

3. To evaluate the prototype by performing usability test to determine target group satisfactions.

\subsection{Scope and Limitations}

This study focuses on developing a conceptual framework for guiding the development of exergames specifically for PD patient. Some of the limitations that have been identified are as follows:

This study focuses only on PD patients in Malaysia that still have the ability to stand and carry out basic movement such as walking. Based on widely used Hoehn and Yahr scale, only PD from stage one to four will be catered for this research. Although this research outcome will be a conceptual framework and a prototype of the game, its main idea is to evaluate the applicability of the framework rather than effectiveness of the rehab by using the exergames.

Another limitation that must be seriously considered includes the capability of the tools that is ought to be used which is Kinect. Kinect has a certain height and range of detection. Optimum height to place Kinect is $85 \mathrm{~cm}$ from the ground [18] which will ensure maximum detection and accuracy of collecting data especially for Parkinson disease patient.

\section{LITERATURE REVIEW}

A monograph was written in 1817 by James Parkinson entitled an essay on the shaking palsy. It is a clear medical type of document dealing with PD. He managed to examine three and observe another three in the streets of London [1] . Parkinson was previously known as 'Paralysis Agitants' and further research have been conducted by Jean-Marin Charcot where later he renames the disease as 'maladie the Parkinson' or PD. Charcot contribution was immense in helping to identify PD. He managed to recognize tremor, rigidity, postural instability and bradykinesia. He even categorized PD as neurological disorder without a known pathological lesion [3].

Currently used diagnostic criteria for PD symptom includes resting tremor, bradykinesia, rigidity and postural imbalance. If two of the symptoms persists, further diagnostic will be carried out. Age factor, exposures to pesticides, positive family history and oophorectomy (removal of ovary to prevent abnormalities) have been identified as risk factor for irregular PD however the caused is still unknown [24]. PD can be categorized as motor and non-motor symptoms. Table 1 shows the motor and non-motor symptoms of PD. 
Table 1 Motor and non-motor symptoms for PD

\begin{tabular}{|l|l|}
\hline \multicolumn{1}{|c|}{ Motor } & \multicolumn{1}{|c|}{ Non-Motor } \\
\hline - Bradykinesia (slowness of & - Autonomic disturbances \\
movements) & (gastrointestinal, urogenital, \\
- Rest tremor & cardiac and respiratory \\
- Rigidity (stiffness) & - Neuropsychiatric dysfunction \\
- Postural and gait & - Olfactory dysfunction \\
impairment & - Sleep behavior disorder \\
[5], [25] & - Other problems including \\
& sensory, skin, sleep and visual \\
& [25], [26] \\
\hline
\end{tabular}

Based on Table 1, motor symptom for PD includes slowness of movements, tremor, stiffness and difficulty to walk. Nonmotor symptoms include constipation, nausea, problem with reproductive organs, hallucination and difficulty to sleep.

In order to determine broad categories in motor function for PD patient, Hoehn and Yahr rating scale is widely been used. The scale was introduced in 1967 [27]. Due to its simplicity and applicability it also has its drawbacks which state the scale is not comprehensive enough. For that reason, a modified version of Hoehn and Yahr have been created (Bhidayasiri \& Tarsy, 2012). Table 2.2 shows the differences between the first version of Hoehn and Yahr scale and modified version of Hoehn and Yahr scale. Based on Table 2, the modified version of Hoehn and Yahr scale is more detail at scale 1 and 2. It provides scale for axial involvement and mild bilateral disease with recovery on pull test.

Table 2 Comparison between Hoehn and Yahr scale and a modified Hoehn and Yarh scale

\begin{tabular}{|c|c|}
\hline $\begin{array}{c}\text { Hoehn and Yahr scale } \\
\text { [27] }\end{array}$ & $\begin{array}{l}\text { Modified Hoehn and Yahr } \\
\text { scale } \\
\text { (Bhidayasiri \& Tarsy, 2012; } \\
\text { Goetz et al., 2004) }\end{array}$ \\
\hline \multirow{2}{*}{$\begin{array}{l}\text { 1. Only } \\
\text { unilateral } \\
\text { involvement, usually with } \\
\text { minimal or no functional } \\
\text { usability. }\end{array}$} & $\begin{array}{l}\text { 1.0 Unilateral involvement } \\
\text { only }\end{array}$ \\
\hline & $\begin{array}{l}\text { 1.5 Unilateral and axial } \\
\text { involvement }\end{array}$ \\
\hline \multirow[t]{2}{*}{$\begin{array}{l}\text { 2. Bilateral or midline } \\
\text { involvement } \\
\text { impairment of balance. }\end{array}$} & $\begin{array}{l}\text { 2.0 Bilateral involvement } \\
\text { without impairment of } \\
\text { balance }\end{array}$ \\
\hline & $\begin{array}{l}\text { 2.5 Mild bilateral disease } \\
\text { with recovery on pull test. }\end{array}$ \\
\hline $\begin{array}{l}\text { 3. Bilateral disease: Mild to } \\
\text { moderate disability with } \\
\text { impaired postural reflexes: } \\
\text { Physically independent }\end{array}$ & $\begin{array}{l}\text { 3.0 Mild to moderate } \\
\text { bilateral disease; Some } \\
\text { postural instability; } \\
\text { Physically independent }\end{array}$ \\
\hline \multirow{2}{*}{$\begin{array}{l}\text { 4. Severely disabling disease; } \\
\text { Still able to walk or stand } \\
\text { unassisted. } \\
\text { 5. Confinement to wheelchair } \\
\text { or bed unless aided }\end{array}$} & $\begin{array}{l}\text { 4.0 Severe disability; Still } \\
\text { able to walk or stand } \\
\text { unassisted }\end{array}$ \\
\hline & $\begin{array}{l}\text { 5.0 Wheelchair bound or } \\
\text { bedridden unless aided }\end{array}$ \\
\hline
\end{tabular}

\section{TREATMENT FOR PARKINSON DISEASE}

Due to major effects in the quality of life of a PD patient, nonmotor symptom have been given great focus in terms of research and treatment [5], [31], [32]. Non-motor symptoms directly affect a PD patient. It affects the quality of life of a patient. Eight dimension of quality of life that is being measured using PDQ 39 (PD Questionnaire) includes mobility, activities of daily living, emotional well-being, stigma, cognition, communication and bodily discomfort (Jenkinson et al., 1997).

\subsection{Drugs}

There are limited drugs available in the marketplace to treat non-motor symptom. Table 2.4 shows the type of drugs currently used to treat non-motor symptom of a PD patient.

Table 3 Type of drugs used to treat non-motor symptoms in PD [33]

\begin{tabular}{|l|l|}
\hline Non-motor syndrome & Type of drugs/Treatment \\
\hline Depression/Apathy & Amitriptyline/SSRIs/Pramipexole \\
\hline $\begin{array}{l}\text { Anxiety and panic } \\
\text { attack }\end{array}$ & $\begin{array}{l}\text { Dopaminergic therapy/ } \\
\text { Anxiolytic therapy }\end{array}$ \\
\hline Hallucinations & Clozapine/Quetiapine \\
\hline Abnormalities of sleep & Modafinil \\
\hline Sexual dysfunction & Sildenafil/Apomorphine \\
\hline Bladder dysfunction & $\begin{array}{l}\text { Oxybutinin/Detrusitol/ } \\
\text { Amitriptyline }\end{array}$ \\
\hline Sialorrhea/Drooling & Botulinum toxic/Sweet things \\
\hline Pain & Dopaminergic therapy \\
\hline
\end{tabular}

Based on Table 3, different type of drugs are used to treat various non-motor symptoms of PD patient. The use of these drugs depends on certain factors which includes age of the patient and co-morbidity [33].

\subsection{Surgery}

Apart from drugs, surgery is another method of treating PD. It comprises deep brain stimulation, ablative lesions and cell transplantation [34]. Table 4 highlights the advantages and disadvantages of surgery.

Table 4 Advantages and disadvantages of each surgery

\begin{tabular}{|l|l|l|}
\hline Surgery & Advantages & Disadvantages \\
\hline $\begin{array}{l}\text { Deep brain } \\
\text { stimulation }\end{array}$ & $\begin{array}{l}\text { Reversible and costs, high } \\
\text { adjustable [34] } \\
\text { risk of infection, the } \\
\text { need for periodic } \\
\text { battery replacement } \\
\text { and potential for } \\
\text { hardware } \\
\text { malfunction [35] }\end{array}$ \\
\hline Ablative lesions & $\begin{array}{l}\text { Improvement in } \\
\text { tremor, } \\
\text { bradykinesia and } \\
\text { rigidity [34] }\end{array}$ & $\begin{array}{l}\text { Hemorrhage, facial } \\
\text { infarction, facial dysphagia, } \\
\text { palsies, } \\
\text { visual field deficit, } \\
\text { affective disorder, } \\
\text { mortality [36] }\end{array}$ \\
\hline Cell transplant & $\begin{array}{l}\text { Improve } \\
\text { symptoms [34] }\end{array}$ & $\begin{array}{l}\text { Still experimental } \\
\text { [34] }\end{array}$ \\
\hline
\end{tabular}

Deep brain stimulation, ablative lesions and cell transplant are surgery method to treat PD. Although deep brain stimulation is reversible and adjustable, it is still considered as high risks. The cost for the surgery is also expensive. Ablative lesions manage to improve tremor, bradykinesia and rigidity but its 
side effect includes other diseases including hemorrhage and infarction. Cell transplant manage to improve symptoms however it is still experimental.

\subsection{Rehabilitation}

PD is treated mostly through pharmalogical (drugs) and surgical but it is unable to address many aspects of the disease. It is one of the reason why rehabilitation have come into place where it manages PD [37].

Rehabilitation processes for PD have various methods. Tai Chi, speech therapy, dance movement, exercise are all part of the rehabilitation process for PD patient. Tai Chi for instant have been proven that it can improve balance, functional capacity and reduced falls [8].

In order to monitor progress of PD patient, a continuous assessment is required. UPDRS or also known as Unified PD Rating Scale is normally being used to evaluate successfulness of a treatment or rehabilitation process.

\section{EXERGAMES}

Ancient Greeks believe that a healthy mind exists in a healthy body. Hence the development of exercise games also known as exergames. Exergames are games that are driven by physical movement [10]. Using various devices such as sensors to detect movement and microphone to detect voice, these tools have widely become a phenomenon in gaming industry and even research. Development of exergames is driven by the lack of physical activity of the public thus causes obesity, cardiac problems and even cancer [38]. Exergames promotes active living and healthier lifestyle [39]. Exergames is not just a game that requires movement. It is also a persuasive technology where it can affect attitude and behavior of human [40]. Staring in 1980s, Amiga Joyboard and Nintendo Powerpad leading the line and not having long term success [41]. Fast forward to the year 2015, well established company such as Microsoft, Nintendo and Sony developed their own devices each known as Kinect, Nintendi Wii and Playstation Move controller. These devices were developed with intention to encourage people to move while playing games. These hardware as well as the games developed for it does not focus only on youngster but to encourage elderly to carry out physical activity while enjoying it at home (Brox \& Hernandez, 2011). Apart from playing games, this hardware has been used even in medical sector. Researches regarding this hardware have been conducted for stroke, Parkinson and even obesity. Entertainment based health intervention have a huge potential to transform healthcare [42].

Health game offers no solution to healing nature but they manage to help people reduce their suffering [42]. Exergames provides an alternative as rehabilitation tools for PD patient. Few researches have taken place regarding rehabilitation for PD using exergames. Exergames (with Kinect as its tools) combine with Finite State Machine (FSM) is used for gait assessment and rehabilitation. The research shows that Kinect is ideal to be put $85 \mathrm{~cm}$ from the ground [18]. Auditory cues can be used to assist PD patient in rehabilitation process [43]. Auditory can be included in the final design of exergames to increase success rate of rehabilitation process. Rehabilitation using exergames must be design based on type of rehabilitation required as well as suitable for the target population [21].
Another method of rehabilitation using exergames is Tai Chi. Kinect based Tai Chi is believed to improve stability of PD patient. This can be done at home and must be carry out regularly. By conducting experiment on two PD patient, positive result of the rehabilitation process have shown [44].

\section{CONCLUSION}

Exergames using Microsoft Kinect v2 is choosen as the best tools for rehabilitation of PD patient. This is due to the fact that it does not require the patient to hold the item while playing hence able to collect useful data. With it wide range camera and does not requires any battery to operate, Microsoft Kinect is the ideal tool. Previous research suggests that by using Kinect as tools, it can maximize capability of exergames in many different areas including retail, manufacturing, advertising and marketing, education and healthcare. Exergames is also capable of carrying out rehabilitation for PD patient. Based on research by Pompeu 2012, there is prove that exergames is effective in helping PD patient to carry out rehabilitation process consistently at home while reducing traveling cost and the needs to hire physical therapist

\section{REFERENCES}

[1] Parkinson, "Essay on Shaking Palsy," 1817.

[2] J. Jankovic, "Parkinson's disease: clinical features and diagnosis.," J. Neurol. Neurosurg. Psychiatry, vol. 79, no. 1957, pp. 368-376, 2008.

[3] C. G. Goetz, "Descriptions and Neurological Therapies," Spring, 2011.

[4] J. C. Ricardo Graca, Rui Sarmento, "ParkDetect," ParkDetect, no. 1, pp. 1-6, 2014.

[5] J. Massano and K. P. Bhatia, "Clinical approach to Parkinson's disease: Features, diagnosis, and principles of management," Cold Spring Harb. Perspect. Med., vol. 2, pp. 1-15, 2012.

[6] C. Jenkinson, R. A. Y. Fitzpatrick, V. I. V Peto, and R. Greenhall, "The Parkinson' s Disease Questionnaire ( PDQ-39 ): development and validation of a Parkinson' s disease summary index score," pp. 353-357, 1997.

[7] T. T. Huang, H. Y. Hsu, B. H. Wang, and K. H. Chen, "Quality of life in Parkinson's disease patients: validation of the Short-Form Eight-item Parkinson's Disease Questionnaire (PDQ-8) in Taiwan.," Qual. Life Res., vol. 20, no. 4, pp. 499-505, May 2011.

[8] E. Eckstrom, R. Stock, J. Galver, G. Maddalozzo, D. Ph, and S. S. Batya, "Tai Chi and Postural Stability in Patients with Parkinson's Disease,” pp. 511-519, 2013.

[9] D. Mccammon, "Medical Food to Stop the Progression of Parkinson 's Disease," no. May, pp. 10-13, 2014.

[10] G. Barry, B. Galna, and L. Rochester, "The role of exergaming in Parkinson's disease rehabilitation: a systematic review of the evidence.," J. Neuroeng. Rehabil., vol. 11, no. 1, p. 33, 2014.

[11] S. D. Atkinson and V. L. Narasimhan, "Design of an introductory medical gaming environment for diagnosis and management of Parkinson's disease," Proc. 2nd Int. Conf. Trendz. Inf. Sci. Comput. TISC-2010, pp. 94-102, 2010.

[12] T. Dutta, "Evaluation of the Kinect ${ }^{\mathrm{TM}}$ sensor for 3-D kinematic measurement in the workplace.," Appl. Ergon., vol. 43, no. 4, pp. 645-9, Jul. 2012. 
[13] P. Rego, P. M. Moreira, and L. P. Reis, "Serious games for rehabilitation: A survey and a classification towards a taxonomy," Inf. Syst. Technol. (CISTI), 2010 5th Iber. Conf., 2010.

[14] B. Galna, G. Barry, D. Jackson, D. Mhiripiri, P. Olivier, and L. Rochester, "Accuracy of the Microsoft Kinect sensor for measuring movement in people with Parkinson's disease.," Gait Posture, vol. 39, no. 4, pp. 1062-8, Apr. 2014.

[15] I. Paraskevopoulos and E. Tsekleves, "Use of gaming sensors and customised exergames for parkinson's disease rehabilitation: A proposed virtual reality framework," 2013 5th Int. Conf. Games Virtual Worlds Serious Appl. VS-GAMES 2013, 2013.

[16] J.-D. Lee, C.-H. Hsieh, and T.-Y. Lin, "A Kinect-based Tai Chi exercises evaluation system for physical rehabilitation," 2014 IEEE Int. Conf. Consum. Electron., pp. 177-178, 2014.

[17] P. Meleiro, R. Rodrigues, J. Jacob, and T. Marques, "Natural User Interfaces in the Motor Development of Disabled Children," Procedia Technol., vol. 13, pp. 6675, 2014.

[18] J. Cancela, M. T. Arredondo, and O. Hurtado, "A Kinectbased system for gait assessment and rehabilitation in Parkinson 's disease," pp. 4519-4522, 2014.

[19] J. Synnott, S. Member, L. Chen, C. D. Nugent, and G. Moore, "WiiPD - Objective Home Assessment of Parkinson' s Disease Using the Nintendo Wii Remote," Trans Inf Technol Biomed, vol. 16, no. 6, pp. 1304-1312, 2012.

[20] B. Galna, G. Barry, D. Jackson, D. Mhiripiri, P. Olivier, and L. Rochester, "Accuracy of the Microsoft Kinect sensor for measuring movement in people with Parkinson's disease.," Gait Posture, vol. 39, no. 4, pp. 1062-1068, Apr. 2014.

[21] B. Galna, D. Jackson, G. Schofield, R. McNaney, M. Webster, G. Barry, D. Mhiripiri, M. Balaam, P. Olivier, and L. Rochester, "Retraining function in people with Parkinson's disease using the Microsoft kinect: game design and pilot testing.," J. Neuroeng. Rehabil., vol. 11, no. 1, p. 60, 2014.

[22] S. Sooklal, P. Mohan, and S. Teelucksingh, "Using the Kinect for Detecting Tremors: Challenges and Opportunities," pp. 768-771, 2014

[23] M. Harms, "Advancing technology in rehabilitation," Physiotherapy, vol. 98, no. 3, pp. 181-182, Sep. 2012.

[24] L. Lau, Incidence, Risk and Prognosis of Parkinson Disease. 2006.

[25] Lima, "Motor and Non-Motor Features of Parkinson's Disease - A Review of Clinical and Experimental Studies," CNS Neurol. Disord. - Drug Targets, vol. 11, no. 4,2012

[26] S. Gallegos, C. Pacheco, C. Peters, C. M. Opazo, and L. G. Aguayo, "Features of alpha-synuclein that could explain the progression and irreversibility of Parkinson's disease," Front. Neurosci., vol. 9, no. March, pp. 1-11, 2015.

[27] M. M. Hoehn and M. D. Yahr, "Parkinsonism: onset , progression , and mortality," vol. 17, no. May, 1967.

[28] R. Bhidayasiri and D. Tarsy, "Movement Disorders: A
Video Atlas," pp. 4-6, 2012.

[29] R. Bhidayasiri and D. Tarsy, "Movement Disorders: A Video Atlas,” pp. 4-6, 2012.

[30] C. G. Goetz, W. Poewe, O. Rascol, C. Sampaio, G. T. Stebbins, C. Counsell, N. Giladi, R. G. Holloway, C. G. Moore, G. K. Wenning, M. D. Yahr, and L. Seidl, "Movement Disorder Society Task Force report on the Hoehn and Yahr staging scale: Status and recommendations," Mov. Disord., vol. 19, no. 9, pp. 1020-1028, 2004.

[31] S. Wishart and G. J. a. Macphee, "Evaluation and management of the non-motor features of Parkinson's disease," Ther. Adv. Chronic Dis., vol. 2, no. 2, pp. 69 85, 2011.

[32] A. Todorova, P. Jenner, and K. Ray Chaudhuri, "Nonmotor Parkinson's: integral to motor Parkinson's, yet often neglected.," Pract. Neurol., pp. 1-13, 2014.

[33] a H. V Schapira, "Present and future drug treatment for Parkinson's disease.," J. Neurol. Neurosurg. Psychiatry, vol. 76, no. 11, pp. 1472-1478, 2005

[34] G. Nicholson, A. C. Pereira, and G. M. Hall, "Parkinson ' s disease and anaesthesia," vol. 89, no. 6, pp. 904-916, 2002.

[35] T. L. Ellis, "Dystonia and the Role of Deep Brain Stimulation," ISRN Surg., vol. 2011, pp. 1-5, 2011.

[36] E. a C. Pereira and T. Z. Aziz, "Surgical insights into Parkinson's disease.," J. R. Soc. Med., vol. 99, no. 5, pp. 238-244, 2006

[37] G. M. Earhart, L. E. Dibble, T. Ellis, A. Nieuwboer, and L. E. Dibble, "Rehabilitation and Parkinson's Disease 2013," vol. 2013, pp. 2013-2014, 2013.

[38] C. Foster, M. Hillsdon, M. Thorogood, and A. Kaur, "Europe PMC Funders Group Interventions for promoting physical activity," no. 1, pp. 1-90, 2014.

[39] M. D. Finco, P. Alegre, and R. W. Maass, "The History of Exergames: Promotion of Exercise and Active Living through Body Interaction," 2014 IEEE 3nd Int. Conf. Serious Games Appl. Heal., pp. 1-6, 2014.

[40] E. Brox and J. E. G. Hernandez, "Exergames for elderly: Social exergames to persuade seniors to increase physical activity," 2011 5th Int. Conf. Pervasive Comput. Technol. Healthc. Work., pp. 546-549, 2011

[41] J. Sinclair, P. Hingston, M. Masek, and K. Nosaka, "Testing an exergame for effectiveness and attractiveness," 2nd Int. IEEE Consum. Electron. Soc. Games Innov. Conf. ICE-GIC 2010, pp. 1-8, 2010.

[42] M. Gotsis, "Games, virtual reality, and the pursuit of happiness," IEEE Comput. Graph. Appl., vol. 29, pp. 1419, 2009.

[43] J. Cancela, E. M. Moreno, M. T. Arredondo, and P. Bonato, "Designing auditory cues for Parkinson' s disease gait rehabilitation," pp. 5852-5855, 2014.

[44] T. Y. Lin, C. H. Hsieh, and J. Der Lee, “A kinect-based system for physical rehabilitation: Utilizing Tai Chi exercises to improve movement disorders in patients with balance ability," Proc. - Asia Model. Symp. 2013 7th Asia Int. Conf. Math. Model. Comput. Simulation, AMS 2013, pp. 149-153, 2013. 